\title{
Early Infant Diagnosis test outcomes and Infants HIV Positivity trends in Kisumu County,
}

Western Kenya

Ogumbo, Fredrick ${ }^{1}$, Ogolla Sidney ${ }^{1}$,Maxwell Majiwa ${ }^{1}$ and Munga Stephen ${ }^{1}$

${ }^{1}$ KEMRI, Centre for Global Health Research, Kisumu

\section{Background}

In infants who acquire HIV at the time of delivery, disease progresses rapidly in the first few months of life, often leading to death. The test for diagnosing infant and children below 18 months is DNAPCR either by dried blood spot or whole blood sample. Due to the persistence of maternal antibodies in infants aged less than 18 months, the use of antibody tests, such as commercially available HIV rapid disposable tests, cannot accurately establish the infants HIV status. Current WHO guidelines call for all HIV-exposed infants to have virological testing at 4-6 weeks of age or at the earliest opportunity thereafter. The qualitative HIV-1 DNA test detects the presence of HIV proviral DNA, a form of the HIV-1 genome produced by the integration of viral DNA into host cell DNA.

\section{Objective}

The main objective was to evaluate EID Positivity outcome trends in Kisumu County, Western Kenya from January to December 2017.

\section{Methodology}

Using information from NASCOP EID Database of Kisumu County from January to December 2017, DNA PCR test outcomes by: positivity trends, age, entry point, mother PMTCT regimen, infant prophylaxis and facility positivity were considered for analysis

\section{Results}

The results showed that from January to December 2017, that a total of 11,579 EID Tests were carried out in Kisumu County, Western Kenya and 454(4.5\%) tests were positive.

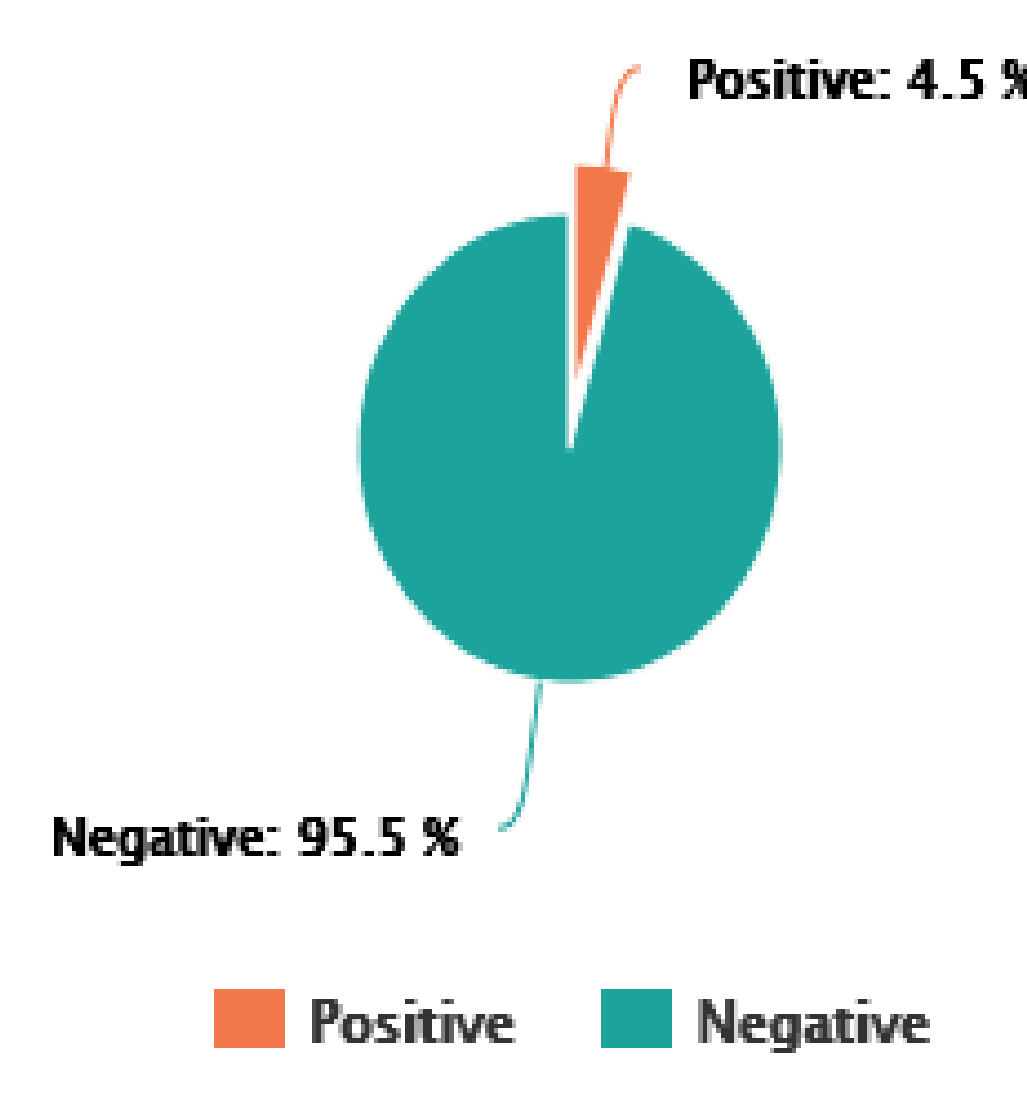

Positivity by Age: EID Positivity outcomes by age showed that $<2$ months-81(2.2\%),2-9months$112(6 \%), 9-12$ months-35 (5\%),12-24 months$33(7.7 \%)$.

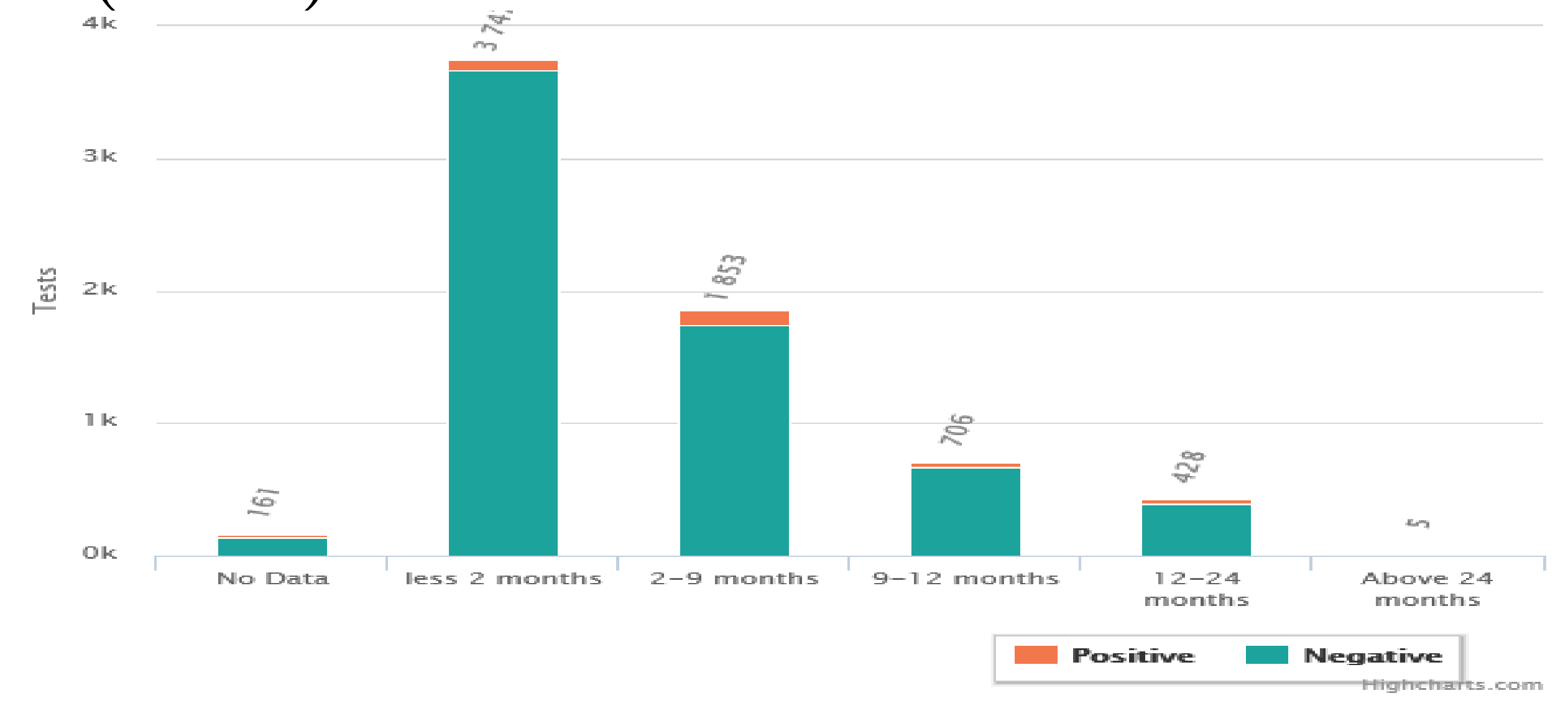

Positivity by entry point: MCH/PMTCT-

219(3.5\%), CCC/PSC-16(4.5\%), No Data-

23(15.1\%), OPD-16(30.8\%), Pediatric-6(15\%), and Maternity $1(8.3 \%)$.

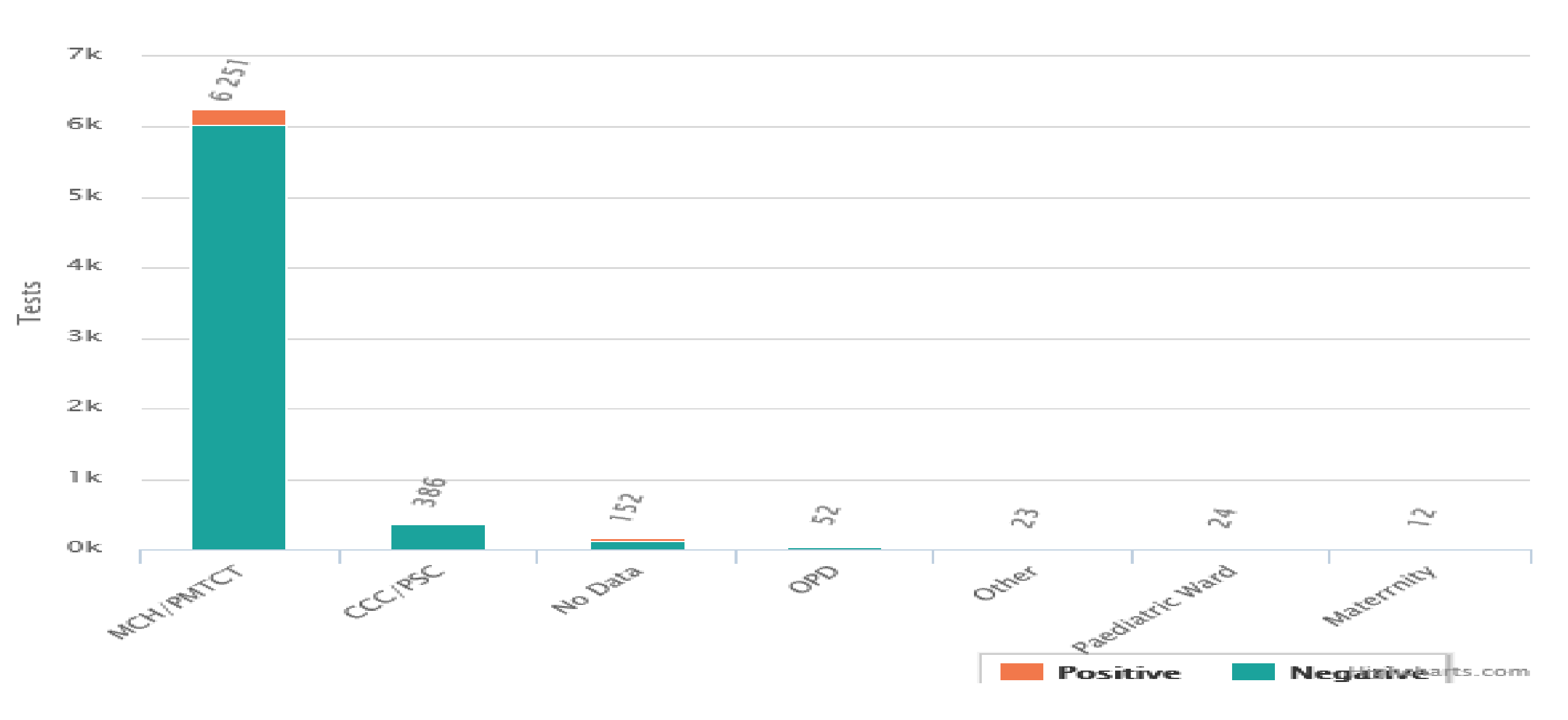

\section{Positivity by Mother PMTCT regimen:}

Results on Positivity by PMTCT regimen: HAART-137(3.4\%), $\quad$ TDF+3TC+EFV$44(2.5 \%), \quad$ TDT $+3 \mathrm{TC}+\mathrm{NVP}-\quad 4(3.1 \%)$, $\mathrm{ADT}+3 \mathrm{TC}+\mathrm{EFV}-8(6.2 \%)$

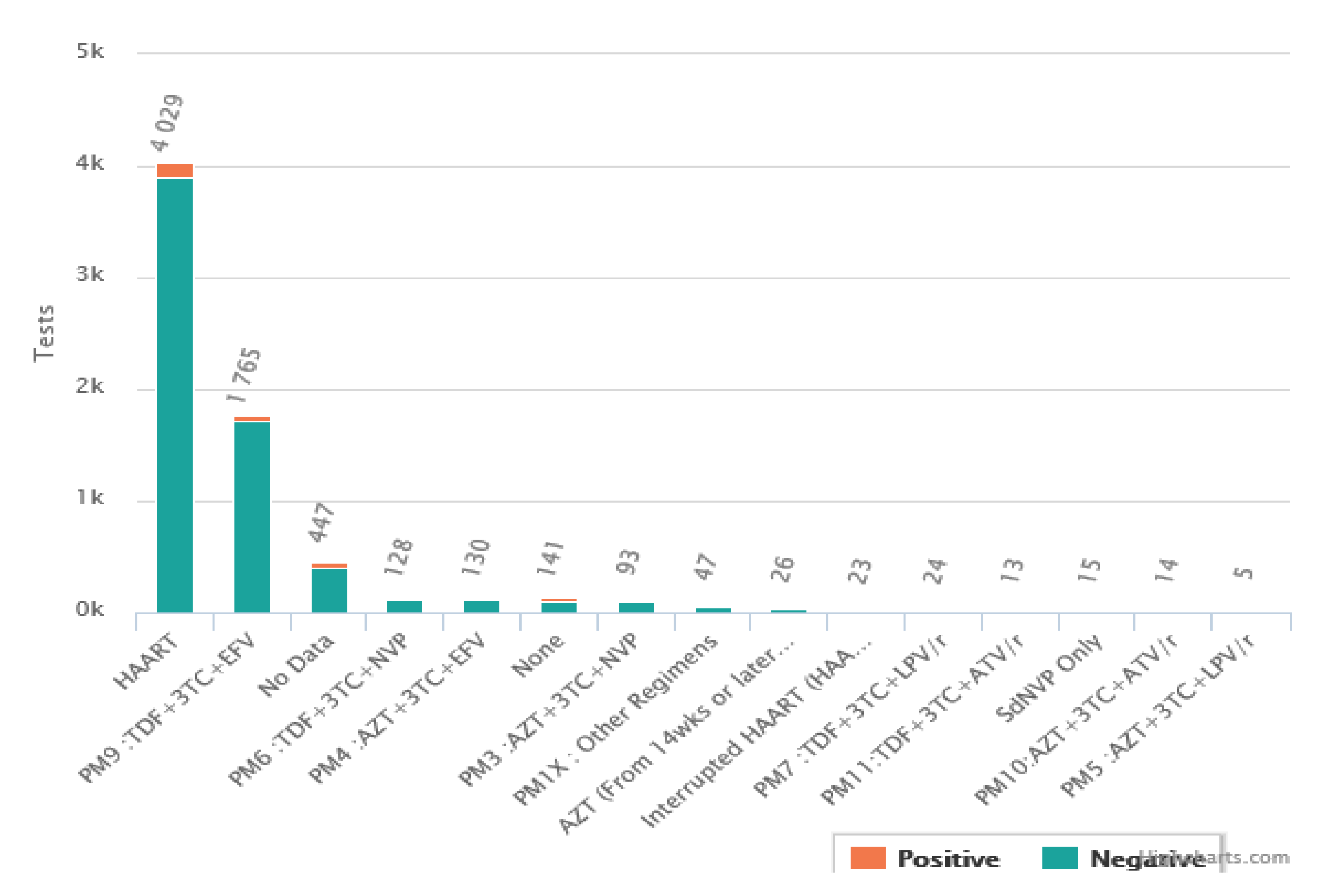

Positivity by infants' prophylaxis: Results on positivity by infant prophylaxis (Initial PCR) showed that: NVP for 6 Weeks 51(3.7\%), NVP during BF$28(3.6 \%)$, and NVP for 12Weeks$.21(3.1 \%), \quad$ NVP+AZT-15(2.2\%), SdNVP only $8(5.3 \%)$.

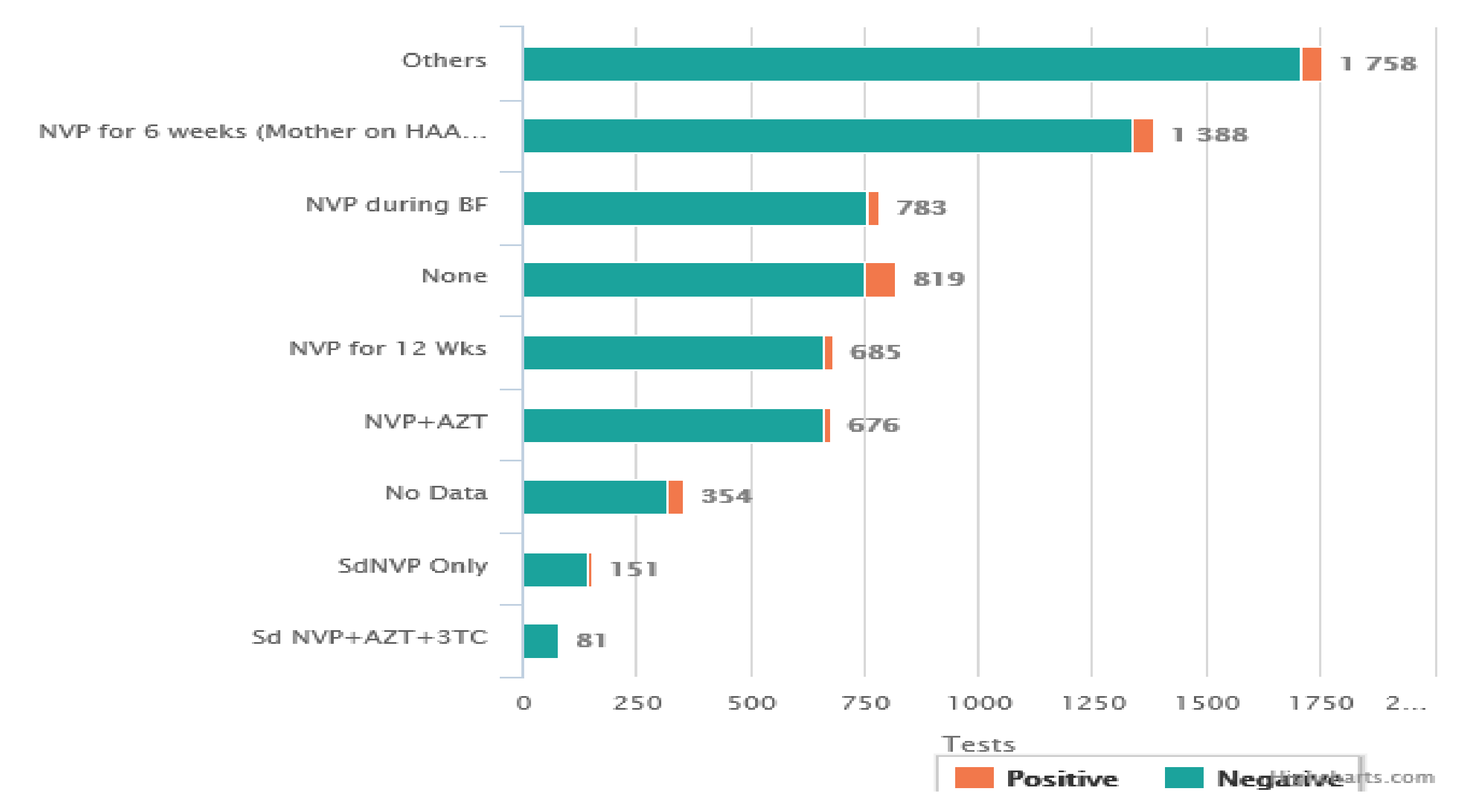

Conclusion

The EID Positivity in Kisumu County, western Kenya is at $4.5 \%$ for the period January to December 2017. Positivity is highest at ages 2-9 months (6\%). Most infants were tested at MCH/PMTCT entry point with a positivity of 3.5\%.The highest positivity was also experienced on infants from mothers on HAART. Infants on NVP for 6 weeks had the highest positivity.

\section{References}

1. Mwau M, Bwana P, Kithinji L, Ogollah F,Ochieng S,Akinyi C, et al. (2017) Mother-to-childtransmission of HIV in Kenya: A crosssectional analysis of the national database over nine years.PLoS ONE12(8):e0183860.https://doi.org/10.1371/journal.pone.0183860

\footnotetext{
2. Newell ML, Coovadia H, Cortina-Borja M, Rollins N, Gaillard P, Dabis F. Mortality of infected and uninfected infants born to HIVinfected mothers in Africa: A pooled analysis. Lancet. 2004;364:1236-43. [PubMed]

\section{3. https://eid.nascop.org/}

4.Consolidated guidelines on the use of antiretroviral drugs for treating and preventing HIV infection: recommendations for a public health approach. Geneva: WHO; June 2013 (http://apps.who.int/iris/bitstre am/10665/85321/1/9789241505727 eng.pdf?ua=1, accessed 2 February 2013).
}

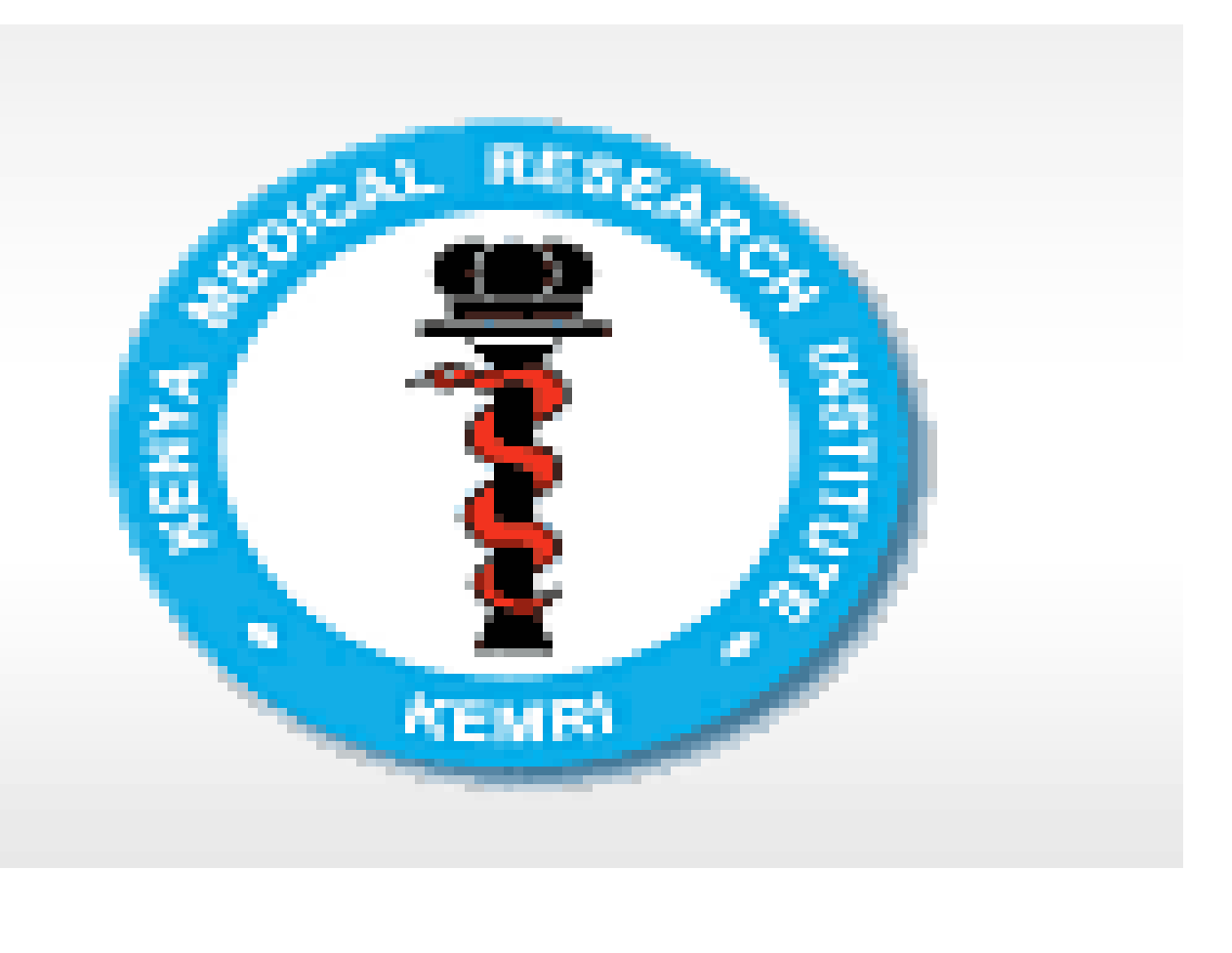

